\section{A ADOLESCÊNCIA, SEUS CONFLITOS E SOLUÇÕES}

Adolescentes. Marta Rezende Cardoso (org.) São Paulo: Escuta, 2006, 216 p.

Pedro H enrique Bernardes Rondon

Psicanalista

Esta é a terceira coletânea de trabalhos sobre a adolescência que a professora doutora Marta Rezende Cardoso organiza, dentro do projeto de pesquisa que coordena sobre o tema no Instituto de Psicologia da UFRJ. Além das duas col etâneas anteriores (Adolescência: reflexões psicanalíticas. Rio de Janeiro: Nau/ Faperj, 1999, e Limites. São Paulo: Escuta, 2004), essa pesquisa também já rendeu um número especial sobre violência psíquica da Pulsional Revista de Psicanálise (São Paulo, ano $X V$, n.163, novembro de 2002).

Em Adolescentes, Marta reuniu artigos de diversos pesquisadores que têm se dedicado às questões dessa importante fase do desenvolvimento psíquico, especialmente do ponto de vista das chamadas patologias contemporâneas.

A clínica psicanalítica vem sendo confrontada, na atualidade, a situações em que predominam os quadros patológicos nos quais prevalecem os mecanismos defensivos mais arcaicos e mais elementares, como as atuações e as passagens ao ato. Nessa difícil ocasião em que devem deixar a situação infantil em di- reção à vida adulta, vivendo profunda perturbação de seu equilíbrio narcísico e pulsional, sendo-Ihes impossível realizar alguma elaboração psicológica dos conflitos que causam tanto sofrimento, os jovens apelam para tais mecanismos que denunciam a precária elaboração de seu estado de desamparo e de desorientação subjetiva.

Nos artigos que compõem a obra são abordados diversos aspectos da adolescência contemporânea, estando presente em todos eles um importante referencial teórico que todo o tempo mostra claramente sua implicação clínica.

A primeira parte do livro se abre com uma entrevista de Jurandir Freire Costa em que são abordadas diversas questões sobre as dificuldades naturais do momento de transição da adolescência na contemporaneidade, como a do enfraquecimento da autoridade, tratadas no seu livro mais recente - 0 vestígio ea aura: corpo e consumismo na moral do espetáculo (Rio de Janeiro: Garamond, 2005).

Em seguida, o artigo de Joel Birman ("Tatuando o desamparo") trabalha a questão das modificações ocorridas na estruturação da sociedade, e particularmente das famílias, desde os anos 1950, mostrando como isso resulta na fragilização identitária da juventude, que já não conta com as definições claras de limites que vigiam na época de seus pais. 0 autor mostra que, ante tal enfraquecimento de sua identidade, os jovens es- 
tão fazendo das tatuagens e dos piercings um meio de obter alguma singularização, uma vez que estes reinscrevem o indivíduo em outras linhagens e ascendências imaginárias, combatendo com isso seu desamparo.

Por meio de um caso clínico em que se evidencia a necessidade de um acerto de contas nas relações com os pais do passado, Elisa Maria de Ulhôa Cintra aborda a questão da adolescência prolongada, afirmando que "não dá para viver bem e sair da adolescência sem perdoar as falhas dos pais".

Luís Cláudio Figueiredo discute alguns aspectos do filme $A$ vida sonhada dos anjos (Erick Zonca, 1998), e chama a atenção para as saídas da adolescência conforme as possibilidades mostradas pelas personagens do filme. Ressal ta o lado do terapeuta na relação com pacientes-limite, quanto à aposta na vida e em seus milagres, oferecendose como mediador na procura de bons objetos que possam permitir a abertura de novos campos de possibilidades, bem como mostrando disponibilidade incansável aos pacientes sem esperanças como a adolescente do filme.

Regina Herzog e Ricardo Salztrager trabalham o sentido da revolta do adolescente na contemporaneidade, tentando extrair desse sentido elementos que contribuam para indicar a possibilidade de reinvenção criativa que 0 adolescente carrega consigo, algo fundamental quando se pretende buscar alternativa criativa para a experiência de limites e potenciais.

Em "Espaço e objetos transicionais na análise de adolescentes borderline", Marion Minerbo apresenta os casos de dois adolescentes cujas análises impuseram a modificação do enquadramento. Utilizando sua experiência em tratamento institucional de adolescentes gravemente perturbados, a autora abriu a possibilidade de outras formas de expressão, fertilizando dessa maneira sua clínica no consultório. Marion mostra que o investimento libidinal do analista em seu paciente no campo transferencial desestabiliza um campo afetivo cristalizado em certa posição sintomática.

Camilo Venturi, Mariana Barbosa eTeresa Pinheiro, em seu artigo, fazem algumas reflexões acerca da questão da vergonha que na atualidade aparece ligada a questões como a performance e a imagem de si mesmo, com excessiva preocupação com o olhar do outro, sugerindo articulações com a situação dos adolescentes no contexto cultural.

"Solidão - isolamento na clínica da adolescência" é o texto em que Ana Cecília Magtaz Scazufca pensa o problema da solidão como viés metodológico para articular o pensamento metapsicológico e a condução clínica da anorexia, da bulimia e da obesidade.

$\mathrm{Na}$ segunda parte da coletânea estão reunidos seis trabalhos que, como coautora, a Marta Rezende Cardoso elaborou juntamente com seus alunos, estagiários da equipe de clínica e pesquisa que coordena na DPA do Instituto de Psicologia da UFRJ.

Amanda Melo, Camila Braz Padrão, Camila Haddad, Carlos Linhares Veloso Filho, Clarice Gomes Palmeira, Elisa Lima Meyerhoffer, Fabiana Lustosa Gaspar, HeIena Aguiar, Lilia Frediani Martins Moriconi, Nataly Netchaeva Mariz, Patrícia Simon Lorenzutti, Paula Ceci Marques da Silva eTatiana Luísa Cerqueira da Silva são esses alunos e estagiários que apresentam suas reflexões sobre importantes aspectos da teoria acerca das dificuldades e dos conflitos próprios à adolescência que se expressam na clínica em quadros diversos, ilustrando suas elaborações com relatos de vinhetas de casos clínicos atendi- 
dos no ambulatório de Departamento de Psicologia Aplicada.

Todos os textos estão escritos em linguagem clara e acessível, de leitura agradável, e certamente vão interessar a quantos se dediquem ao aprofundamento do estudo de questões relativas à adolescência e às chamadas patologias próprias da contemporaneidade. A forma da apresentação em textos tão bem escritos e mesmo didáticos dá à coletânea o caráter de livro que poderá ser aproveitado por estudiosos de todos os níveis, mesmo por aqueles que ainda se encontram em processo de formação - acadêmica, nos cursos de graduação e pós-graduação, tanto quanto de formação psicanalítica.

Recebida em 26/ 4/ 2006.

Pedro Henrique Bernardes Rondon phrondon@br.inter.net

\section{O ENSINO DA CLÍNICA DAS PSICOSES}

\section{Clínica psicanalítica das psicoses.}

Ricardo de Sá, Maria Lídia Oliveira de Arraes Alencar, Giselle Falbo e Cláudio Oliveira (orgs.) Niterói: EdUFF, 2005, $124 \mathrm{p}$.

\section{Angela C. Bernardes \\ Psicanalista, aderente da Escola Brasileira de Psicanálise-Seção Rio, professora da Universidade Federal Fluminense (UFF)}

0 que o psicótico ensina àquele que pratica a clínica psicanalítica e o que se pode ensinar dessa experiência clínica são os dois eixos que orientaram a discussão proposta por integrantes do Laboratório de Psicanálise e Laço Social (Lapso), da
Universidade Federal Fluminense. Tal discussão, por sua vez, é conseqüência do encontro destes professores com a clínica realizada na rede de Saúde Mental de Niterói, através da associação do curso de Especialização do Lapso/ UFF com a Residência de Saúde Mental da Secretaria de Saúde de Niterói.

0 livro é composto de quatro partes com três artigos cada, reunindo assim os 12 artigos apresentados no Colóquio “Clínica psicanalítica das psicoses", realizado na UFF, em julho de 2004.

$\mathrm{Na}$ primeira parte, Letícia Martins Balbi, Paulo Vidal e Ricardo de Sá, abordam diferentes aspectos do ensino da psicanálise com respeito à clínica da psicose. Ricardo de Sá contrapõe ensino e transmissão para propor que a perplexidade frente à psicose tem efeitos na transmissão da psicanálise, pois esta perplexidade advém do encontro com uma radical alteridade, diferença absoluta que implica na impossibilidade de se responder pela via da compreensão. Servindo-se de fragmentos clínicos trazidos a ela por alunos e residentes, em orientações e supervisões, Letícia Balbi tira alguns ensinamentos disso. De forma clara e bem apoiada na experiência, verifica que os fenômenos psicóticos apontam para a estrutura significante como distinta da função de comunicação e significação e para o engodo da tentativa de "compreender": "abordar, por exemplo, as intuiç̧ões delirantes pela perspectiva da significação é, de certa forma, participar da própria estrutura delirante". Paulo Vidal interroga, em essência, sobre o lugar que cabe ao analista para um sujeito que, diferentemente do neurótico, não interroga o Outro, pois o Outro já lhe respondeu. Essa discussão, ilustrada por um caso de sua clínica, vem no bojo da reflexão sobre as possibilidades de se ensinar 0 que a psicanálise ensina. 